\title{
The Impact of 5S Strategy on the Safety Climate \& Productivity at Egyptian Garment Firms (Assembly Plants)
}

\author{
K. M. Seddik \\ Textile Division, National Research Centre, Giza, Egypt \\ Email: dr.khaledseddik@gmail.com
}

How to cite this paper: Seddik, K.M. (2019) The Impact of 5S Strategy on the Safety Climate \& Productivity at Egyptian Garment Firms (Assembly Plants). Open Journal of Business and Management, 7, 1072-1087.

https://doi.org/10.4236/ojbm.2019.72073

Received: March 25, 2019

Accepted: April 26, 2019

Published: April 29, 2019

Copyright (c) 2019 by author(s) and Scientific Research Publishing Inc. This work is licensed under the Creative Commons Attribution International License (CC BY 4.0).

http://creativecommons.org/licenses/by/4.0/

\begin{abstract}
$5 S$ is one of the lean manufacturing tools that helps organizations to improve the work environment. The philosophy of $5 \mathrm{~S}$ interesting on eliminating waste and non-value activity which increases labour efficiency and work area safety. Although many articles stated the significant impact of implementing lean manufacturing in worker environment, non-quantifiable results were reported. In this article, the impact of the $5 \mathrm{~S}$ event on the safety climate and productivity at the assembly plant of Egyptian garment firms was studied. The sample was divided into two groups based on $5 \mathrm{~S}$ implementation. The Safety Climate Assessment Tool survey (SCAT) was used in measuring the perceptions of safety on a Likert-scale while three productivity metric was calculated. The result presented that $5 \mathrm{~S}$ has a significant impact on 7 of 8 topics of safety climate. The management commitment $\&$ the priority of safety climate at Egyptian garment firms need to be developed while usage a no-blame approach to persuade people acting safely has to be increased. In the same context, the results assigned that productivity measures influenced by $5 \mathrm{~S}$ event.
\end{abstract}

\section{Keywords}

Lean Manufacturing, 5S Event, Safety Climate, Productivity Measures, Egyptian Garment

\section{Introduction}

Manufacturers face several challenges, e.g. rising costs, inefficiencies, and low of quality and safety by implementing process improvement techniques. Lean is a well-established set of principles which aim at reducing waste. It is used prominently due to its effectiveness and simplicity. 
Lean, in theory, is supposed to improve the working conditions of the employees and eliminate the hazards in the workplace as well [1]. There are even a few instances where researchers have shown improvements in occupational safety through lean, but they are limited [2]. Basically due to other critical issues like delivery, quality and customer satisfaction, occupational safety is lost. Therefore provide evidence of lean affecting occupational safety is required.

The target of this study is to seek the potential relationship between lean and safety climate of assembly workers. $5 \mathrm{~S}$ is the lean technique investigated in this study. The subject area is the assembly department at a manufacturing facility.

\section{Literature Review}

\subsection{Lean Manufacturing}

Although the origin of the lean manufacturing traced to the early days of Ford Motor Company, the development came by the Japanese automobile industry after World War II. Lean manufacturing defined by Toyota motor as a management philosophy with a set of tools which attend to eliminate waste, reducing costs and improving quality [3]. In addition, the lean methodology aims to improve the value as perceived by customers by ensuring timely service or delivery. Table 1 demonstrates the seven wastes which were mentioned in the Toyota Production System (TPS) [4].

By the times, the application of lean principles from the Toyota Production System has developed to a more customer value orientation. Definition of value related to the capability of the organization to achieve customer requirements in minimal time. In this respect, the value was divided into two sections as added-value and non added-value. Added-value identified as critical steps in serving and delivering products to a customer while non added-value should be removed

Table $1.7^{\text {th }}$ wastes in manufacturing from TPS.

\begin{tabular}{|c|c|}
\hline Wastes & Description \\
\hline Overproduction & $\begin{array}{l}\text { Producing too much or too soon, resulting in poor flow of information or goods } \\
\text { and excess inventory. }\end{array}$ \\
\hline Inventory & $\begin{array}{l}\text { Excessive storage and delay of information or products, resulting in excess } \\
\text { inventory and costs, leading to poor customer service. }\end{array}$ \\
\hline Motion & $\begin{array}{l}\text { Poor workplace organization, resulting in poor ergonomics, e.g., excessive } \\
\text { bending or stretching and frequently lost items. }\end{array}$ \\
\hline Transportation & $\begin{array}{l}\text { Excessive movement of people, information or goods, resulting in wasted time } \\
\text { and cost. }\end{array}$ \\
\hline $\begin{array}{l}\text { Inappropriate } \\
\text { processing }\end{array}$ & $\begin{array}{l}\text { Going about work processes using the wrong set of tools, procedures or systems, } \\
\text { often when a simpler approach may be more effective. }\end{array}$ \\
\hline Defects & $\begin{array}{l}\text { Frequent errors in paperwork or material product quality problems resulting in } \\
\text { scrap and/or rework. }\end{array}$ \\
\hline Wasting & $\begin{array}{l}\text { Long periods of inactivity for people, information or goods, resulting in poor } \\
\text { flow and long lead-times. }\end{array}$ \\
\hline
\end{tabular}


[5]. This results in placing customer value and waste reduction at the centre of lean [6]. Lean in manufacturing facilitates streamline operations, decreasing the lead time, inventory and eliminating wastes, in beside that its focus on increasing financial savings and customer satisfaction [6] [7]. Recent researches have cited that organizations have realized enormous achievements due to implementing lean principles. Reference [8] stated that executing lean manufacturing lead to improving performance in terms of productivity and quality. This clarifies the potential of improving quality while simultaneously decreasing the cost of manufacturing facilities.

\subsection{S Lean Manufacturing}

$5 \mathrm{~S}$ is a powerful lean procedure which improves work environment through eliminating waste and non-value activities consequently, increase the product quality and employees morals. Some researchers identify it as a system which help workers to think differently, while others see it as an organizer tool, however they all agree that it's an effective \& simplest lean manufacture [9] [10].

$5 S$ translated from five Japanese principles that start with the letter " $S$ " to five equivalent English words as Sort, Set in order, Shine, Standardize, and Sustain [9]. Figure 1 presents the principles of 5S.

\section{Description of the 5S Program}

According to [8], 5S is a technique where waste is eliminated as well as productivity and quality are improved through organizing the work area.

1S: Sort: Concentrates on segregated between necessary and unnecessary items at work area.

2S: Set In Order: focuses on place the collected items from previous S "sort" in its proper location which help in saving time (Lead Time).

3S: Shine: Interest in maintaining the production area. After implementing

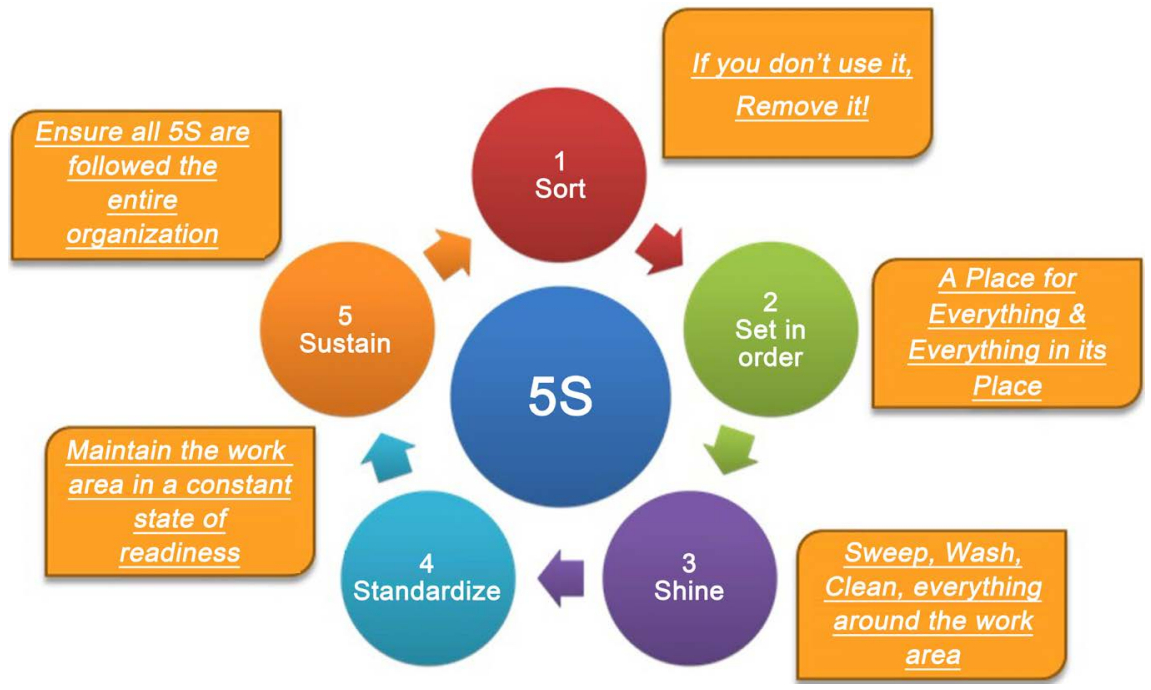

Source: Redesign by author.

Figure $1.5 \mathrm{~S}$ principles. 
the first two elements eliminate waste and locate the needed items, the shine step began to clean the work area.

4S: Standradize: Aim to allow employees to implement the best practices in the entire organization by standardizing methods.

5S: Sustain: Sustain is almost considered as the most difficult " $S$ " to implement, as many employees tendency to return to the old way of doing things. Sustain step emphasis on maintaining the whole system by the meaning of accountability, commitment and empowering.

\section{Benefits of a $5 S$ program}

- Magnify visibility.

- Eliminate waste.

- Increase sense of ownership \& morale.

- Improved productivity-minimizing the time spent searching for tools, materials, etc.

- Save time (Lead time).

- Improved quality, maintenance \& safety.

- A better impression on customers.

\subsection{Safety Climate}

Several industries such as construction and aviation give careful consideration to evaluating safety [11]. Basically, safety assessment had been based on reactive measures (reported data on worker fatalities and injuries). However, human factors \& organizational are involved in different incidents. So currently, many industries are interesting on predictive measures of safety [11]. Safety climate regarded as a predictive measure of safety, than others traditional safety measures which are reactive [12].

Most of the researchers have been defined safety climate in terms of worker attitudes towards safety. Reference [13] stated that safety climate returns to safety habitude of employees in a working plant, while according to [14], safety related to employees perceptions toward procedures and practices in an organization (reflect the value of safety).

Generally, the term of safety culture utilized in an integrated way with safety climate despite they have varied perceptions and have been studied individually [12]. While security culture points to the general convictions existing in an establishment, safety climate is more identifying to attitudes and employees perceptions' for both internal and external impacts [15]. Reference [16] signified that the safety climate is a more proper term for the investigations from the surveys.

\section{Safety Climate in Industrial}

Safety climate is viewed as the best instrument for estimating work safety environment in manufacturing facilities. Reference [17] referred to that the regular strategies for estimating safety are incomplete and others different components are wanted to genuinely comprehend the safety in a work environment. Employees' perceptions, safe practices, management commitment are imperative 
parts to be comprehended to understand the general significance of safety in the manufacturing segment. Therefore, Safety climate measuring tool, which includes all these elements, acquires a great importance.

Safety climate measuring tool was evolved by several researchers in order to include varied dimensions for measuring the employees' perceptions of safety. In fact, there is no particular safety survey, which is considered the most effective measuring tool due to their relevant models which differ from manufacturer to others [18] [19] [20] [21]. In this study dimensions like safety rules \& procedures, management role, worker empowering are extremely important due to the fact that they may be impacted by implementing 5S. Therefore, according to the prerequisites, the safety climate survey utilized in this article is the Safety Climate Assessment Toolkit (SCAT) which was produced by the UK Health and Safety Executive (HSE) [22]. This was initially produced for oil extraction organizations, but over time became one of the standout amongst the most ordinarily connected polls in the manufacturing industries too [23].

\subsection{Safety \& Lean}

The lean concepts of eliminating waste, optimizing the process flow, and increasing the quality lead to reduce work area hazard and improve safety [24]. Although several researchers presented the significant impact of implementing lean manufacturing in worker safety, non-quantifiable results were reported. This ultimately fails in substantiating the real relationship between lean and worker safety.

\section{Methodology}

The research was performed in the assembly area at Egyptian garment establishments. The sample was divided into two groups based on $5 \mathrm{~S}$ implementation according to [25]. Group (A) (the most applicable to 5S event) represented $52.9 \%$ of the total sample while group (C) (the lowest applicable) $47.1 \%$. The statistical analysis based on comparing collected data of the safety climate from two groups while the productivity measures were calculated.

\subsection{Safety Climate Survey}

The Safety Climate Assessment Tool survey (Appendix) was used in this investigation. The SCAT contains 43 questions with 8 different topics (Table 2).

The perceptions of safety were measured on a Likert-scale (Table 3). T-tests with a difference in the SCAT scores (Final Score \& Section wise scores) were analyzed with 0.05 level of significance.

\subsection{Productivity Measures}

The effectiveness of the $5 \mathrm{~S}$ event was tested using three productivity measures.

\subsubsection{Cycl Time}

The cycle time in this study was estimated by time study, using a stopwatch (or a 
Table 2. Different topics of SCAT.

\begin{tabular}{cc}
\hline Topics & Items \\
\hline Management Commitment & 7 \\
Communication & 5 \\
Priority of Safety & 7 \\
Supportive Environment & 6 \\
Involvement & 3 \\
Personal Priorities and Need for Safety & 5 \\
Personal Appreciation of Risk & 4 \\
Work Environment & 6 \\
\hline
\end{tabular}

Table 3. Safety climate survey scale.

\begin{tabular}{cc}
\hline Rating & Scale \\
\hline Strongly Disagree & 1 \\
Disagree & 2 \\
Neutral & 3 \\
Agree & 4 \\
\hline
\end{tabular}

phone). Using the accessible data, the actual number of cycles to be measured was computed using Equation (1).

$$
N=\left(\frac{Z \cdot S}{E}\right)^{2}
$$

where,

$N=$ Final number of cycles to be observed.

$Z=$ Value from the $\mathrm{Z}$ table ( $\mathrm{Z}=1.96$ for $95 \%$ confidence interval).

$E=$ Accuracy $( \pm 5 \%) \times$ Average cycle.

$S=$ Standard Deviation of the cycle time.

\subsubsection{Floor Space}

A successful $5 \mathrm{~S}$ event usually frees the available floor space previously held up by unnecessary items. Increased floor space is one of the visual indicators of a successful $5 \mathrm{~S}$ event. The available floor space was measured.

\subsubsection{Inventory}

Inventory (parts ready to be assembled) in the assembly area, This measure was monitored along with units produced on 6 particular day. A ratio between the inventory and the number of units produced in the particular day was calculated.

\section{Results and Discussion}

\subsection{Safety Climate}

Based on t-test, the p-value of the total and individual scores of the safety cli- 
mate (SCAT Tool) for the two groups was calculated as shown in the Table 4. The total scores indicated a significant difference between the two groups. Furthermore, the results pointed that communication was the only item which realized an insignificant level among other safety climate tools. The justification return that in fact, 5S event wasn't directly influence on communication as it relied on personal safety perception than management interaction. On beside that the results defined that involvement was the most affected while the supportive environment was the lowest.

In order to demonstrate the impact of the $5 \mathrm{~S}$ system on safety climate of assembly workers in each group, the investigation rate of the SCAT items for every topic was calculated and presented in a line chart as follows.

\subsubsection{Management Commitment}

As shown in (Figure 2) management commitment of safety is more effective at group (A) than group $(\mathrm{C})$. This could be attributed to the strict management

Table 4. Paired t-test result of the safety climate dimensions.

\begin{tabular}{|c|c|c|c|c|c|}
\hline \multirow{2}{*}{ (SCAT) Dimensions } & \multicolumn{2}{|c|}{ Group C } & \multicolumn{2}{|c|}{ Group A } & \multirow{2}{*}{ P Value } \\
\hline & $\mathrm{SD}$ & Mean & $\mathrm{SD}$ & Mean & \\
\hline Management Commitment & 2.312953 & 21.27586 & 1.863574 & 22.51724 & 0.022159922 \\
\hline Communication & 1.784581 & 14.55172 & 1.162849 & 15.06897 & 0.161872768 \\
\hline Priority of Safety & 1.378941 & 22.48276 & 1.901516 & 21.48276 & 0.024655982 \\
\hline Supportive Environment & 1.645265 & 17.27586 & 1.162849 & 18.06897 & 0.049151554 \\
\hline Involvement & 0.976321 & 8.896552 & 0.939028 & 9.896552 & 0.000387826 \\
\hline $\begin{array}{l}\text { Personal Priorities and Need } \\
\text { for Safety }\end{array}$ & 1.536902 & 16.82759 & 1.472239 & 17.89655 & 0.011217272 \\
\hline Personal Appreciation of Risk & 1.323341 & 12.41379 & 1.212618 & 11.44828 & 0.015112675 \\
\hline Work Environment & 1.038662 & 18.31034 & 0.902924 & 17.62069 & 0.017204833 \\
\hline Total & 4.101243 & 132.0345 & 3.654743 & 134 & 0.048481282 \\
\hline
\end{tabular}

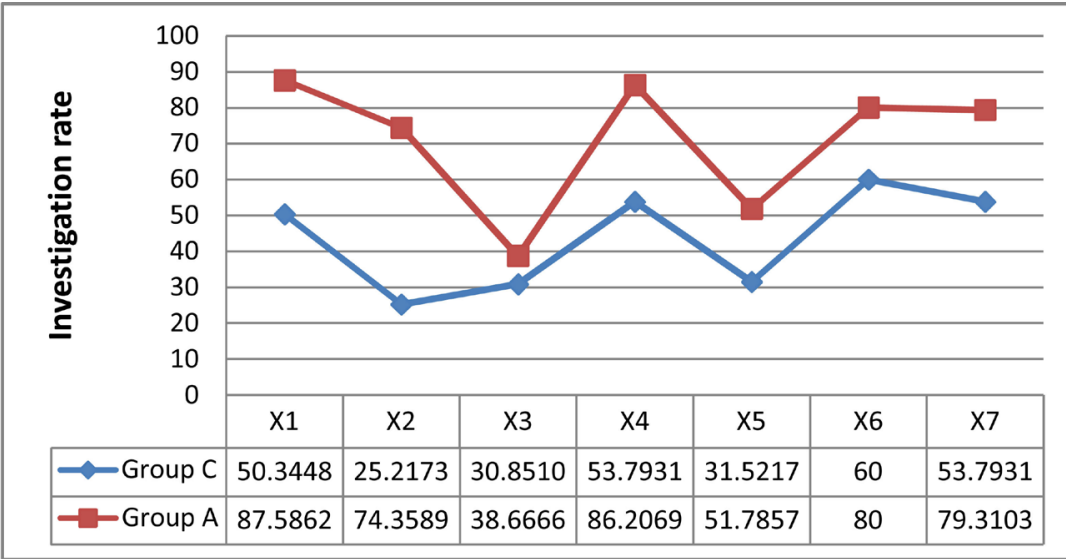

Source Own Study.

Figure 2. Investigation of management commitment items in each group. 
standards which were set up as a part of 5S standardize phase to emphasize improving work area and eliminating hazards which lead to reduce production time.

In addition, the result presented that although the group (A) act decisively and quickly to correct safety problems, the corrective actions are always taken when management is told about unsafe practices. Furthermore, the result revealed a contradictory situation at group (C) where, in spite of interesting in safety, management acts only after accidents have occurred. This concludes that management commitment to safety climate at Egyptian garment enterprises require a supporter system such as monitoring or alarming systems to detect the safety hazards and assigned a proper solution as fast as it can.

\subsubsection{Communication}

The result in a Figure 3 reflects the influence of $5 \mathrm{~S}$ implementation on the communication topic of safety climate, where the group (A) (more $5 \mathrm{~S}$ applicable) achieving a higher implementation than the group (C) (less $5 \mathrm{~S}$ applicable). The explanation related to $5 \mathrm{~S}$ philosophy which powers employees' involvement and enhances their responsibility toward work improvements

Moreover, the results demonstrated that the highest communication policy at the group (A) traced to a continuous attention about safety information, while at the group (C) linked to approach an open door policy on safety issues. In the same vein the result clarified that the lowest policy at the two groups returned to the praise for working safety, which refer that sensitivity of safety issue may be decreased if the administration didn't innovate a new procedures to empower and encourage labors.

\subsubsection{Priority of Safety}

Figure 4 presents a magnitude effect of $5 S$ event on the priority of safety, where the group $(\mathrm{A})$ are more considering to priority of safety than group $(\mathrm{C})$. In addition, the results stated that although the group (A) following safety rules carefully \& regarding safety as important to production, some safety rules and procedures

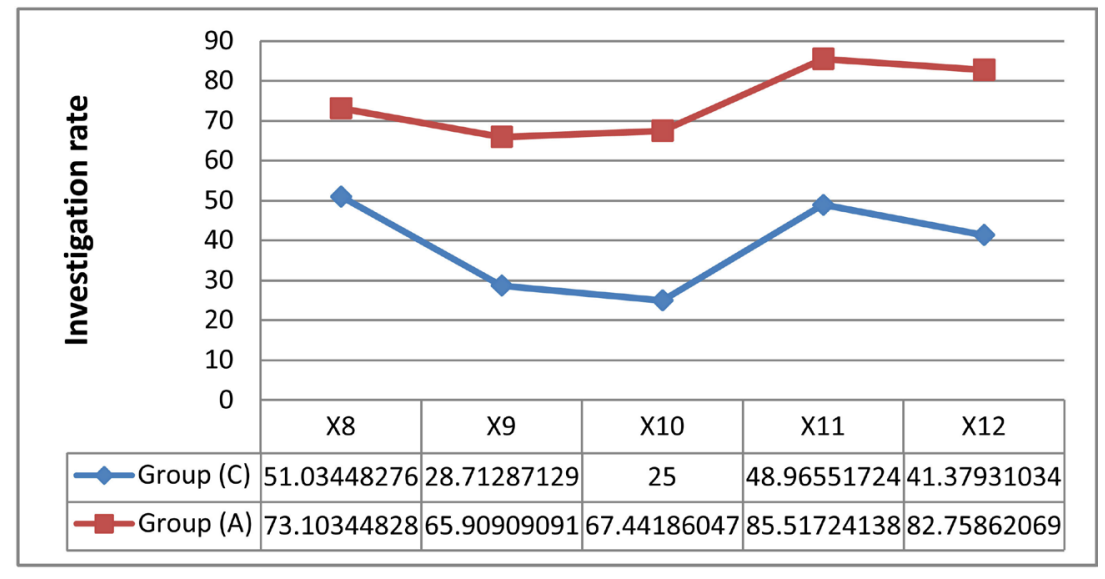

Source: Own Study.

Figure 3. Investigation of communication items in each group. 
need to be developed in order to support occupational safety with respect to productivity. On the other hand, the result illustrated that while, the management of group (C) clearly considers the safety of employees of great importance, sometimes its depart from safety requirements for production's sake indicating to necessary for carrying out more training and engagements.

\subsubsection{Supportive Environment}

The Scores in Figure 5 identify that group (A) conducts more concentrations on three topics to improve the environment of safety. 1) Cooperation on how to work safely, 2) encouraging to report unsafe conditions and 3) safety responsibility. While on Group (C) the main item associated to interact employees for safety work. On the other way, the result presented that the lowest item at the two groups related to using a no-blame approach to persuade people acting unsafely that their behavior is inappropriate which spotted to the possibility of decreasing on the supportive environment of safety with time. Generally, the chart in Figure 4 demonstrates that the supportive environment of safety climate on a group $(\mathrm{A})$ is more investigated than group $(\mathrm{C})$.

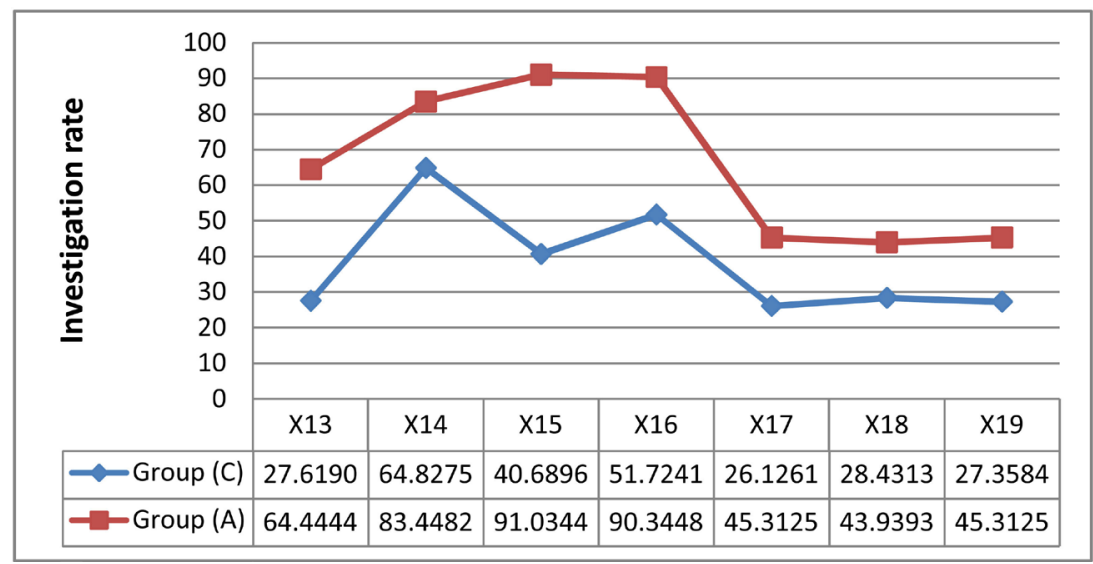

Source: Own Study.

Figure 4. Investigation of priority items in each group.

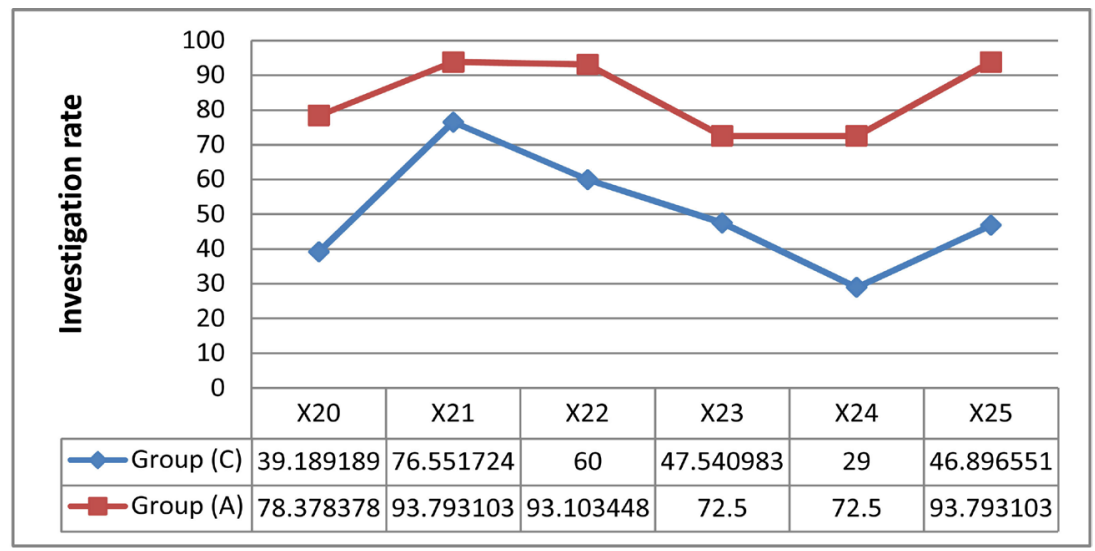

Source: Own Study.

Figure 5. Investigation of supportive environment items in each group. 


\subsubsection{Involvement}

Relying on the findings at Figure 6, group (A) accomplishes a higher execution of involvement than group $(\mathrm{C})$ which refers to a significant effect of $5 \mathrm{~S}$ methodology on administration visions. At the same time, the results refer to a contradictory situation at the two groups as however involving employees with safety issues attained the highest rating, the joining in the ongoing review achieved the lowest, indicating to the necessity of building a strategy that increases the effectiveness of staff's involvement in safety climate to ensure sustainability.

\subsubsection{Personal Priorities \& Needs}

The impact of $5 \mathrm{~S}$ methodology on personal priorities and needs for safety is presented in Figure 7 where the results stated that the personal priorities of safety are more increasing at the group (A) than group (C). Besides that, the results pointed that understanding the safety rules for the job are the most varied between the two groups.

Moreover, the results clarified that in spite of decreasing on personal priorities

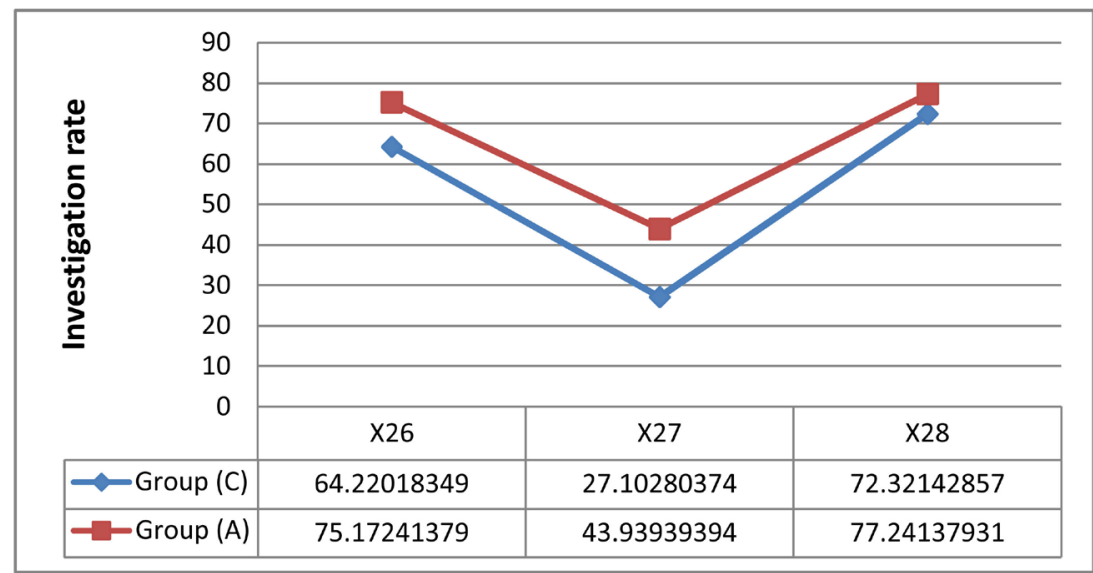

Source: Own Study.

Figure 6. Investigation of involvement items in each group.

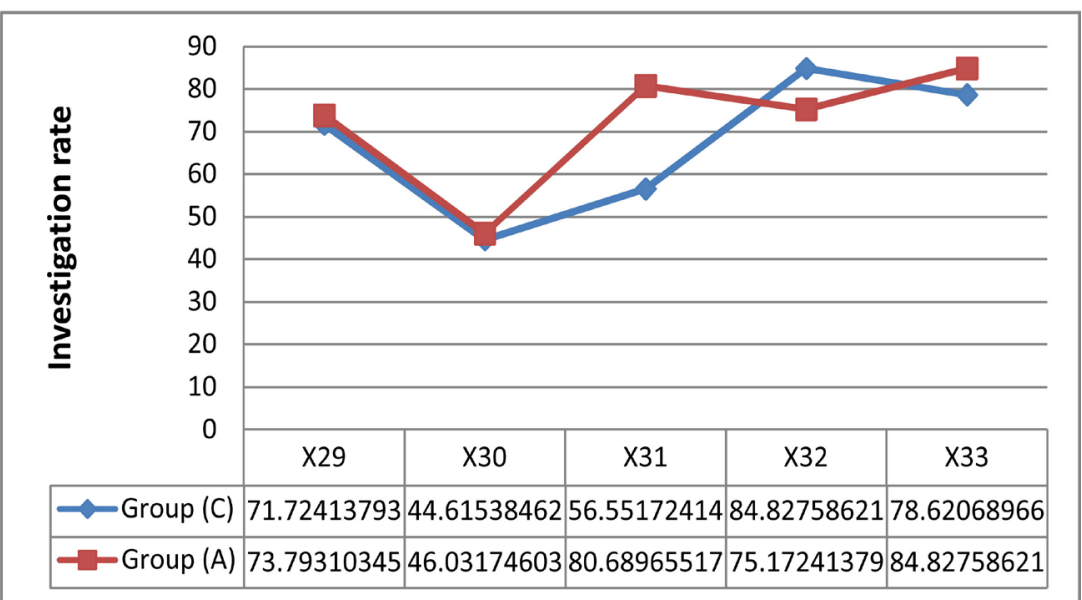

Source: Own Study.

Figure 7. Investigation of personal priorities and needs items in each group. 
and needs for safety at the group (C), employees are more considering to emphasis on safety than other group reflecting the potential of improvement can be in sample manner.

\subsubsection{Personal Appreciation of Risk}

Figure 8 demonstrates the line chart for personal appreciation of risk. The results declared the magnitude of $5 \mathrm{~S}$ event in appreciation of risk where the group (A) achieved a higher scores (meaning a lower risk and more safety implementation) than group (B).

Furthermore, the scores showed that workers at the two groups were rarely worried about being injured on the job, but at the same time they sure it's only a matter of time before involved in an accident, which identifies that sustaining $5 \mathrm{~S}$ practices need to be developed in a following manner:

1) Training should occur on a regular basis from top management to the labor force.

2) Equipment \& tools should be placed on their allocated point and the pieces of the garment should be maintained in the defined area.

3) All procedures should be updated and adhered to on a daily basis.

4) An evaluation should be performed and kept as required for assessment at the end of each month.

\subsubsection{Work Environment}

The effectiveness of $5 \mathrm{~S}$ principles on the work environment of safety climate was demonstrated in Figure 9, where the group (A) realized a higher implementation than group (C). In addition the results present that the highest investigation of the two groups returned to availability of enough people to get the job done safely while the lowest investigation connected to time reduction to get the job done safely which refer that standardize of time at Egyptian garment enterprises require more development and practicing in order to achieve target production in a safe manner.

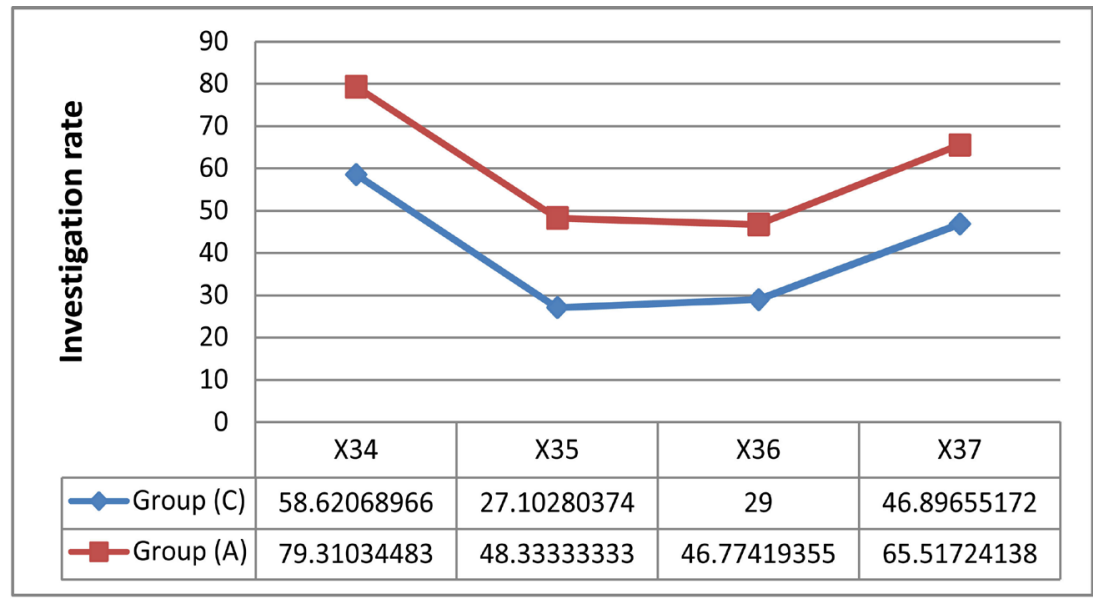

Source: Own Study.

Figure 8. Investigation of personal appreciation of risk items in each group. 


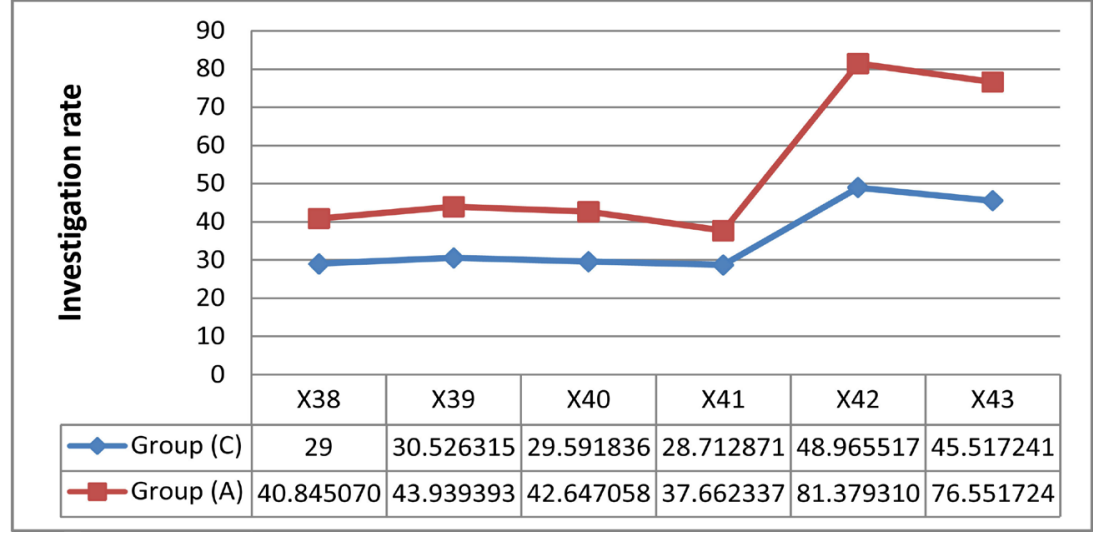

Source: Own Study.

Figure 9. Investigation of work environment items in each group.

\subsection{Productivity Measures}

\subsubsection{Cycle Time}

The cycle time was defined as the time it takes the assembly worker to assemble a unit (T-shirt) with all the parts. All the parts were already available on the workstation. The average of total time for group (C) to assemble T-shirt parts was 46 minutes approximately (2.3) minutes per unit, as measured with 12 samples while The total time for group (A) to assemble was 42 minutes $\sim(2.1) \mathrm{mi}$ nutes/unit which is a $8.69 \%$ decrease. This showed that the $5 \mathrm{~S}$ event effectively reduced the cycle time of assembling a unit

\subsubsection{Floor Space Utilization}

The floor space utilized by the assembly for material storage, handling and aisles were measured. In group $(C)$ the average of the total area utilized by the assembly was $41.5 \mathrm{~m}^{2}$ while the floor space utilized by the group (A) assembly was 52.7 $\mathrm{m}^{2}$, which is a $26.9 \%$ increase. The explanation related to $5 \mathrm{~S}$ attribution to remove unnecessary equipment and parts which took up space in the workplace (the first stage: sort) and standardize of a pull concept as opposed to the traditional push concept which resulted in moving the units to the next step immediately after completion. So, the units were never placed on the floor, which freed up space (The fourth stage: standardization).

\subsubsection{Inventory Held up}

A ratio (inventory held up to the number of units finished) was calculated. Lower ratio equaled to better inventory management. A mean ratio of group (C) was 6.38 per unit ( $\$ 146,866$ in inventory held up to 23 units finished), while the mean ratio of group (A) was 3.74 per unit ( $\$ 119,833$ in inventory held up to 32 units finished). The ratio decreased by $41.3 \%$. This showed that the $5 \mathrm{~S}$ event effectively reduced the inventory held up in the assembly area.

\section{Conclusions}

$5 S$ has a significant impact on 7 of 8 topics of safety climate. Communication was 
the only item which realized insignificant level among other safety climate tools.

The results stated that the management commitment $\&$ the priority of safety climate at Egyptian garment firms needs to be developed. As well as, increasing usage of a no-blame approach to persuade people acting safely to support work environment shall be magnified. Contradictory situations were observed, referring to the necessity for more empowering, practicing and accountability. The results assigned that productivity measures influenced by $5 \mathrm{~S}$ event, where the production cycle time decreased, the utilized floor space increased and the inventory reduced.

On the other hand, the results presented the strong positive relation between $5 \mathrm{~S}$ polices and safety climate where group A (the most applicable to $5 \mathrm{~S}$ event) achieved a higher investigation of the SCAT items than group C (the lowest applicable) which provide evidence of lean affecting occupational safety.

\section{Acknowledgements}

The author would like to thank the National Research Center for funding the research and to all laborers, supervisors, and managers at Egyptian garment firms for their response and interactions.

\section{Conflicts of Interest}

The author declares no conflicts of interest regarding the publication of this paper.

\section{References}

[1] Ohno, T. (1978) Toyota Production System: Beyond Large-Scale Production. Diamond Inc., Tokyo.

[2] Rahman, M.N.A., Khamis, N.K., Zain, R.M., Deros, B.M. and Mahmood, W.H.W. (2010) Implementation of 5S Practices in the Manufacturing Companies: A Case Study. American Journal of Applied Sciences, 7, 1182-1189.

https://doi.org/10.3844/ajassp.2010.1182.1189

[3] De Koning, H., Verver, J.P.S., van den Heuvel, J., Bisgaard, S. and Does, R.J.M.M. (2006) Lean Six Sigma in Healthcare. Journal for Healthcare Quality, 28, 4-11. https://doi.org/10.1111/j.1945-1474.2006.tb00596.x

[4] Hines, P. and Taylor, D. (2000) Going Lean. Lean Enterprise Research Centre, Cardiff.

[5] Womack, J. and Jones, D. (2003) Lean Thinking. Simon \& Schuster, New York.

[6] Al-Araidah, O., Momani, A., Khasawneh, M. and Momani, M. (2010) Lead-Time Reduction Utilizing Lean Tools Applied to Healthcare: The Inpatient Pharmacy at a Local Hospital. Journal for Healthcare Quality, 32, 59-66.

https://doi.org/10.1111/j.1945-1474.2009.00065.x

[7] Melton, T. (2005) The Benefits of Lean Manufacturing: What Lean Thinking Has to Offer the Process Industries. Chemical Engineering Research and Design, 83, 662-673. https://doi.org/10.1205/cherd.04351

[8] Bayo-Moriones, A., Bello-Pintado, A. and Merino-Díaz de Cerio, J. (2010) 5S Use in Manufacturing Plants: Contextual Factors and Impact on Operating Performance. International Journal of Quality \& Reliability Management, 27, 217-230. 
https://doi.org/10.1108/02656711011014320

[9] Becker, J.E. (2001) Implementing 5S to Promote Safety \& Housekeeping. Professional Safety, 46, 29-31.

[10] Hill, A.V. (2010) Encyclopedia of Operations Management. Clamshell Beach Press, Eden Prairie, MN.

[11] Colla, J.B., Bracken, A.C., Kinney, L.M. and Weeks, W.B. (2005) Measuring Patient Safety Climate: A Review of Surveys. Quality and Safety in Health Care, 14, 364-366. https://doi.org/10.1136/qshc.2005.014217

[12] Clarke, S. (2006) Contrasting Perceptual, Attitudinal and Dispositional Approaches to Accident Involvement in the Workplace. Safety Science, 44, 537-550. https://doi.org/10.1016/j.ssci.2005.12.001

[13] Donald, I. and Canter, D. (1993) Psychological Factors and the Accident Plateau. Health and Safety Information Bulletin, 215, 5-12.

[14] Neal, A. and Griffin, M.A. (2004) Safety Climate and Safety at Work. In: Barling, J. and Frone, M.R., Eds., The Psychology of Workplace Safety, American Psychological Association, Washington DC, 15-34. https://doi.org/10.1037/10662-002

[15] Glendon, A.I. (2005) Safety Culture. In: Karwoski, W., Ed., International Encyclopedia of Ergonomics and Human Factors, Taylor and Francis, London.

[16] Mearns, K., Whitaker, S.M. and Flin, R. (2001) Benchmarking Safety Climate in Hazardous Environments: A Longitudinal, Interorganizational Approach. Risk Analysis, 21, 771-786. https://doi.org/10.1111/0272-4332.214149

[17] Baek, J.-B., Bae, S., Ham, B.-H. and Singh, K.P. (2008) Safety Climate Practice in Korean Manufacturing Industry. Journal of Hazardous Materials, 159, 49-52. https://doi.org/10.1016/j.jhazmat.2007.07.125

[18] Gillen, M., Baltz, D., Gassel, M., Kirsch, L. and Vaccaro, D. (2002) Perceived Safety Climate, Job Demands, and Coworker Support among Union and Non-Union Injured Construction Workers. Journal of Safety Research, 33, 33-51. https://doi.org/10.1016/S0022-4375(02)00002-6

[19] Hayes, B.E., Perander, J., Smecko, T. and Trask, J. (1998) Measuring Perceptions of Workplace Safety: Development and Validation of the Work Safety Scale. Journal of Safety Research, 29, 145-161. https://doi.org/10.1016/S0022-4375(98)00011-5

[20] Lee, T.R. and Harrison, K. (2000) Assessing Safety Culture in Nuclear Power Stations. Safety Science, 34, 61-97. https://doi.org/10.1016/S0925-7535(00)00007-2

[21] Zohar, D. (2002) The Effects of Leadership Dimensions, Safety Climate, and Assigned Priorities on Minor Injuries in Work Groups. Journal of Organizational Behavior, 23, 75-92. https://doi.org/10.1002/job.130

[22] Cox, S.J. and Cheyne, A.J.T. (2000) Assessing Safety Culture in Offshore Environments. Safety Science, 34, 111-129. https://doi.org/10.1016/S0925-7535(00)00009-6

[23] Tomás, J.M., Cheyne, A. and Oliver, A. (2011) The Relationship between Safety Attitudes and Occupational Accidents: The Role of Safety Climate. European Psychologist, 16, 209-219. https://doi.org/10.1027/1016-9040/a000036

[24] Ikuma, L.H., Nahmens, I. and James, J. (2011) Use of Safety and Lean Integrated Kaizen to Improve Performance in Modular Home Building. Journal of Construction Engineering \& Management, 137, 551-560. https://doi.org/10.1061/(ASCE)CO.1943-7862.0000330

[25] Seddik, K.M. (2017) Studying the Implementation of 5S System in Egyptian Garment Enterprises. International Journal of Industrial and Manufacturing Engineering, 11, 1925-1928. https://waset.org/Publication/10008172 


\section{Appendix: Safety Climate Assessment Toolkit}

\begin{tabular}{lll}
\hline Q No. Question & $\begin{array}{l}\text { Strongly } \\
\text { disagree }\end{array}$
\end{tabular} disagree $\begin{aligned} & \text { Neither Agree } \\
& \text { nor Disagree }\end{aligned}$\begin{tabular}{l} 
Agree $\begin{array}{l}\text { Strongly } \\
\text { Agree }\end{array}$ \\
\hline
\end{tabular}

\section{Management Commitment}

X1 Management acts decisively when a safety concern is raised

X2 Management acts only after accidents have occurred

X3

Corrective actions are always taken when management is told about unsafe practices

$\mathrm{X} 4$ In my workplace management acts quickly to correct safety problems

X5 In my workplace management turn a blind eye to safety issues

X6 In my workplace managers/supervisors show interest in my safety

X7 Managers and supervisors express concern if safety procedures are not adhered to

\section{Communication}

X8 Management operates an open door policy on safety issues

X9 My supervisor does not always inform me of current concerns and issues

X10 I do not receive praise for working safely

X11 Safety information is always brought to my attention by my line manager/supervisor

X12 There is good communication here about safety issues which affect me

\section{Priority of Safety}

X13 I believe that safety issues are not assigned a high priority

X14 Management clearly considers the safety of employees of great importance

X15 Safety rules and procedures are carefully followed

X16 Management considers safety to be equally as important as production Safety Rules and Procedures Sometimes it is necessary to depart from safety requirements for production's sake

X18 Some health and safety rules and procedures are not really practical Some safety rules and procedures do not need to be followed to get the job done safely

\section{Supportive Environment}

X20 Employees are not encouraged to raise safety concerns

X21 Co-workers often give tips to each other on how to work safely

X22 I am strongly encouraged to report unsafe conditions

X23 When people ignore safety procedures here, I feel it is none of my business behavior is inappropriate

X25 I can influence health and safety performance here

\section{Involvement}

X26 I am involved in informing management of important safety issues 


\section{Continued}

X27 I am never involved in the ongoing review of safety

X28 I am involved with safety issues at work

\section{Personal Priorities and Need for Safety}

X29 Safety is the number one priority in my mind when completing a job

X30 Personally, I feel that safety issues are not the most important aspect of my job

X31 I understand the safety rules for my job

X32 It is important to me that there is a continuing emphasis on safety

X33 A safe place to work has a lot of personal meaning to me

\section{Personal Appreciation of Risk}

X34 I am rarely worried about being injured on the job

X35 In my workplace the chances of being involved in an accident are large

X36 I am sure it is only a matter of time before I am involved in an accident

X37 I am clear about what my responsibilities are for health and safety

\section{Work Environment}

X38 I cannot always get the equipment I need to do the job safely

X39 Operational targets often conflict with safety measures

X40 Sometimes conditions here hinder my ability to work safely

X41 Sometimes I am not given enough time to get the job done safely

X42 There are always enough people available to get the job done safely

X43 This is a safer place to work than other companies I have worked for 